\title{
PENYELEKSI BARANG BERDASARKAN TINGGI BERBABIS MICROCONTROLLER ATMEGA 8535 DENGAN KONVEYOR
}

\author{
I Gede Krisnu Wardana ${ }^{1}$, Nyoman Gunantara ${ }^{2}$, Nyoman Pramaita ${ }^{3}$ \\ Program Studi Teknik Elektro, Fakultas Teknik, Universitas Udayana \\ Email: email krisnuwardana3@gmati.com²ㄴ. gunantara@unud.ac.id ${ }^{2}$, ${ }^{2}$ Pramaita@ee.unud.ac.id ${ }^{3}$
}

\begin{abstract}
ABSTRAK
Permasalahan yang sering terjadi dalam penyeleksi barang, masih banyak industri yang membuat konveyor sebagai pengirim barang saja tanpa proses seleksi. Tujuan penelitian ini adalah membuat alat prototype penyeleksi barang berdasarkan tinggi mengunakan mikrokontroler ATMega 8535. Ditemukan bahwa alat prototipe penyeleksi barang berdasarkan tinggi berbasis mikrokontroler ATMega 8535 dengan konveyor berkerja maksmal. Konveyor 1 akan bergerak jika ada barang atau benda yang di letakan di depan konveyor 1 dan berhenti ketika barang berada di ujung konveyor 1. Konveyor 2 akan bergerak jika sensor photodioda sudah mendeteksi tinggi barang yang ada di konveyor 1. Seluruh pengujian dilakukan berkerja dengan baik. Sensor photodioda sudah bekerja dengan baik ketika digunakan untuk mengukur tinggi benda atau barang. Penelitian merekomendasikan penyempurnaan lebih lanjut dengan menambahkan pengembangan prototipe yang lebih rumit sehingga diharapkan bisa di aplikasikan pada industri dan pabrik sebenarnya. Alat ini hanya dapat mengukur tinggi barang maka dari itu bisa di kembangkan missal warna atau berat barang.
\end{abstract}

Kata Kunci : ATMega 8535, konveyor, tinggi barang.

\begin{abstract}
Problems that often occur in the selection of goods, there are still many industries that make conveyors as senders only without a selection process. The purpose of this study was to make a high-variable item selection prototype tool using an ATMega 8535 microcontroller. It was found that the prototype goods selection tool was based on a high ATMega 8535 microcontroller with a maximum working conveyor. Conveyor 1 will move if there is an item or object that is left in front of conveyor 1 and stops the goods at the end of the conveyor 1. Conveyor 2 will move if the photodiode sensor has detected the items on the conveyor 1. All tests are performed properly. The photodiode sensor works well to measure the height of objects or items. Further improvements with more complex development prototypes that can be applied to actual industries and factories. This tool can only measure the height of the item from what can be developed or the weight of the item..
\end{abstract}

Keywords: ATMega 8535, conveyor, high.

\section{PENDAHULUAN}

Perkembangan teknologi dalam praktik industri turut serta dalam meningkatkan efisiensi proses produksi, hal ini sejalan dengan meningkatnya permintaan konsumen terhadap barang produksi yang meningkat setiap tahunnya. Pengembangan teknologi dalam proses produksi bertujuan untuk meningkatkan efisiensi, efektivitas dan kecepatan proses produksi. Terutama dalam proses seleksi, monitoring dan pemrosesan bahan baku. Proses seleksi dalam proses produksi agar dapat berjalan dengan baik dan benar di butuhkan optimasi yang baik dan sesuai dengan kenyataan. Permasalahan yang sering terjadi dalam proses pengemasan dan seleksi barang, masih banyak industri yang menggunakan konveyor yang berfungsi hanya untuk barang saja karena bentuk barang yang berbeda, sehingga ketika sebuah salah satu konveyor tidak dapat begerak maka barang tidak akan bergerak.Sehingga dibutuhkan sistem dan monitoring secara otomatis sehingga membutuhkan waktu lebih singkat, akurat, dan efisien.

Penelitian terdahulu dilakukan Bhuana (2014) dengan judul Purwarupa Sistem Sorting Barang Berdasarkan Warna Menggunakan Mikrokontroler ATMEGA16 Dengan Sensor Photodioda, penelitian tersebut menemukan bahwa mikrokontroler keluaran dari ATMEL dengan seri Atmega16 dan menggunakan software yang di gunakan untuk mendownload progam ke mikrokontroler atmega16 bernama USB AP memiliki efisiensi yang lebih baik dari sistem sebelumnya 
[3]. Penelitian berikutnya dilakukan Ariandana (2014) berjudul Rancang Bangun Konveyor Untuk Sistem Sortir Barang berdasarkan Berat Barang, pembuatan Mekanik konveyor pada alat tersebut harus menggunakan PVC Belt supaya lebih elastis [5]. Temuan Ariandana (2014) menjelaskan bahwa pada saat penimbangan dan memilah barang mencapai 75\% dikarenakan ada error saat memilah. Selenoid tidak mampu mendorong dengan tepat pada objek sehingga sistem perlu dilakukan peningkatan [5].

Pada penelitian ini peseleksi barang digunakan secara otomatis berupa alat konveyor belt di lengkapi dengan mikrokontroler ATMega 8535 dan photodioda sebagai sensor tinggi benda. Penggerak konveyor adalah motor DC. Ada 2 buah konveyor yaitu Konveyor1 dan konveyor 2 . Konveyor pertama di gunakan sebagai konveyor pengumpan barang, yang di lengkapi dengan photodiode, sedangkan di konveyor kedua merupakan tempat sortir barang, dimana terdapat 3 buah tempat peletakan barang untuk tinggi yang berbeda beda. Kecepatan motor pada konveyor 2 dapat di atur menggunakan control Pulse Width Modulation (PWM). Untuk Sistem Control rangkaian memonitoring sistem menggunakan Rangkaian minimum sistem mikrokontroler. Atmega8535 memliki 4 port yang dapat di gunakan untuk banyak masukan dan keluaran, memiliki ADC, Timer dan fasilitas lainya. Peneliti menggunakan mikrokontroler ATMega 8535 dengan keuntungan mudah digunakan karena tidak memerlukan downloader yang sangat merepotkan seperti ATMega16, selain itu dapat diprogam menggunakan sistem minimalnya [2]. Sistem monitoring menggunakan mikrokontroler ATMega 8535 dengan pemograman pada Vision AVR [3]. Pada dasarnya AVR studio menggunakan bahasa pemograman Assembler. AVR studio juga dapat menggunakan bahasa $\mathrm{C}$ sebagai bahasa pemograman. Tujuan penelitian ini adalah membuat alat prototype penyeleksi barang berdasarkan tinggi mengunakan mikrokontroler ATMega 8535.

\section{KAJIAN PUSTAKA}

\subsection{ATMega 8535}

ATMega 8535 adalah mikrokontroler CMOS 8 bit daya rendah berbasis arsitektur RISC. Intruksi di kerjakan pada satu siklus clock, ATMega8535 mempunyai throughput mendekeati MIPS per $\mathrm{Hz}$, hal ini membuat ATMega 8535 dapat bekerja dengan kecepatan tinggi walaupun dengan penggunaan daya rendah. Mikrokontroler Atmega8535 memiliki beberapa fitur atau spesifikasi yang menjadikanya sebuah solusi pengendali yang efektif untuk berbagai keperluan
[1].

\subsection{Motor DC}

Motor DC adalah motor listrik yang merlukan suplai tegangan arus searah pada kumparan medan untuk di ubah menjadi energi gerak mekanik[4]. Kumparan medan pada motor dc disebut stator dan kumparan jangkar yang di sebut rotor. Motor arus searah, sebagaimana namanya menggunakan arus langsung yang tidak langsung.

\subsection{Sistem Minimum Mikrokontroler}

Sistem minimum Mikrontroler ATMega 8535 merupakan rangkian minimum yang di buat agar sistem ini dapat berkerja dan berfungsi dengan semestinya. Sistem minimum ini meliputi catu daya mikrokontroler (vcc) yang berkisar antara 2,7 V-5,5V. Kristal oscillator yang berfungsi sebagai referensi kecepatan akses mikrokontroler, Kristal oscillator diperlukan jika menginginkan referensi clock yang tinggi, tanpa Kristal oscillator pun mikrokontroler masih dapat bekerja karena sudah memiliki referensi clock internal [10].

\subsection{Photodioda}

Photodiode atau dalam bahasa Indonesia di sebut dengan diode foto adalah komponen elektronika yang dapat mengubah cahaya menjadi arus listrik. Dioda foto merupakan komponen aktif ynag terbuat dari bahan semikonduktordan tergolong dalam kerluarga dioda. Seperti dioda pada umumnya, Photodioda atau diode photo ini memilki dua kaki terminal yaitu kaki terminal katoda dan kaki terminal anoda, namun diode foto memiliki lensa dan filter optic yang terpasang dipermukaanya sebagai pendeteksi cahaya[9].

\subsection{AVR Studio 4}

AVR Studio adalah sebuah software Intregrated Development Environment (IDE) yang di buat oleh ATMEL untuk membuat aplikasi pemograman 8 bit pada mikrokontroler AVR. Pada dasarnya AVR studio 4 menggunakan bahasa pemograman Assembler. Bahasa pemograman Assembler adalah bahasa tingkat rendah yang memiliki ke unggulan sendiri namun sulit untuk di pahami. Selain menggunakan bahasa pemograman assembler , AVR studio juga dapat menggunakan bahasa C sebagai bahasa pemograman [6].

\subsection{Konveyor}

konveyor adalah sistem mekanis yang memiliki fungsi memindahkan barang dari satu tempat ke tempat lain. Konveyor banyak digunakan dalam industri untuk mengangkut barang yang sangat besar dan berkelanjutan. Dalam kondisi tertentu, Konveyor banyak digunakan karena mereka memiliki nilai ekonomis 
dibandingkan dengan transportasi berat, seperti lori dan alat transportasi [7]. Konveyor dapat terus memindahkan barang dalam jumlah besar dari satu tempat ke tempat lain. Perpindahan lokasi harus memiliki posisi tetap sehingga sistem transportasi memiliki nilai ekonomi. Kelemahan sistem ini adalah bahwa ia tidak memiliki fleksibilitas ketika posisi barang yang dimobilisasi tidak tetap dan jumlah elemen yang dimasukkan tidak berkelanjutan.

\section{METODE PENELITIAN}

Penelitian alat ini dilakukan di Laboratorium Sistem Telekomunikasi, Jurusan Teknik Elektro dan Komputer, Fakultas Teknik, Universitas Udayana, Bukit Jimbaran. Penelitian ini dimulai pada bulan Maret 2018 sampai dengan selesai.

\subsection{Perancangan Perangkat Keras}

Perancangan pada Penyeleksi Barang Berdasarkan Tinggi Berbasis Microcontroller Atmega8535 dengan Conveyor dapat dilihat pada diagam blok sistem peseleksi barag berbasis Microcontroller Atmega8535 berdasarkan tinggi ditunjukkan pada Gambar 1. Data Sample di letakan pada konveyor 1. Kemudian di jalankan menuju sensor. Hasil dari pendeteksian sensor di transmisikan ke Atmega8535. Kemudian Mikrokontroler Atmega8535 akan berkomunikasi dengan konveyor 2 untuk menentukan hasil akhir.

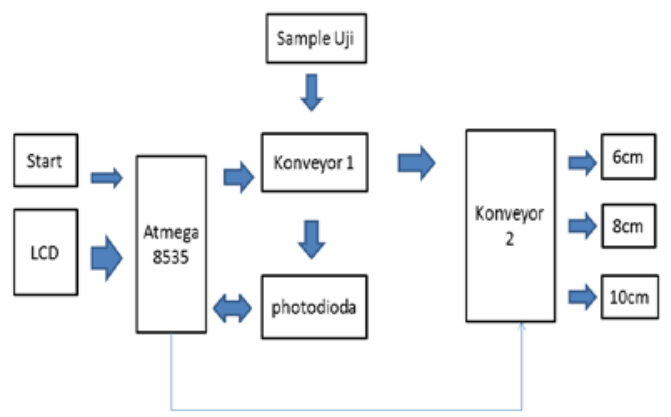

Gambar 1. Diagram blok sistem Perangkat Peseleksi barang

\subsection{Diagram Alir Perancangan Perangkat Secara Keseluruhan}

Diagram alir keseluruhan menggambarkan proses pembuatan sistem Peseleksi Barang Berdasarkan Tinggi Berbasis microcontroller ATMega 8535 dengan Konveyor, perancangan hardware, perancangan software, dan proses pengujian. Pada proses perancangan blok diagram sistem dilakukan perancangan secara umum blokblok rangkaian yang di butuhkan dalam pembuatan sistem. Kemudian dilanjutkan dengan proses perancangan perangkat keras untuk setiap blok rangkaian. Pada tahapan ini dilakukan perancangan skematik dan lay out PCB untuk setiap blok rangkaian. Diagram alir perancangan Perangkat Penseleksi barang dapat di lihat pada Gambar 2.

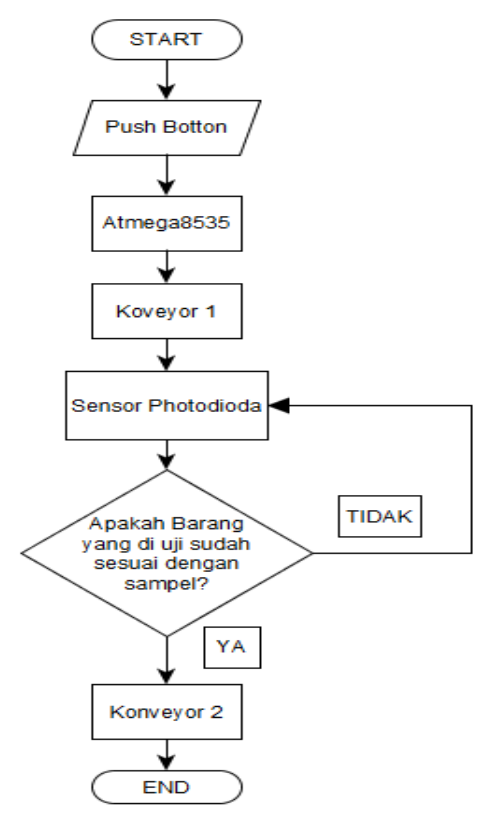

Gambar 2. Diagram alir keseluruhan Perancangan Perangkat Peseleksi Barang Berdasarkan Tinggi Berbasis Microcontroller ATMEGA8535 dengan Conveyor

\section{HASIL DAN PEMBAHASAN}

\subsection{Realisasi Hasil Perancangan}

Sistem monitoring peseleksi barang merupakan suatu alat yang digunakan untuk melakukan pemisahan barang berdasarkan tinggi menggunakan mikrokontroler ATMega 8535. Proses pemisahanya dengan konveyor dan di identifikasi oleh sensor photodioda. Alat ini dioperasikan dengan cara peletakan barang di konveyor 1, Konveyor 1 akan bergerak otomatis jika sensor 1 di letakan barang secara bergantian dengan ketinggian berbeda. Barang yang telah di letakan di sensor pertama akan menuju ke sensor ke dua. Disensor kedua terdapat 4 buah sensor yang di gunakan untuk mengukur tinggi barang. Setelah pengukuran tinggi barang akan menuju sensor 3 yang di gunakan untuk mengetahui bahwa barang sudah melewati konveyor 1 dan jatuh pada konveyor 2 . Hasil penyeleksi barang akan ditampilkan dalam LCD. Pada konveyor 2 terdapat 4 Box untuk penyimpanan barang yang sesuai dengan tinggi barang. Realisasi hasil perancangan dari sistem Penyeleksi barang berdasarkan tinggi dengan konveyor dapat dilihat pada gambar 3. 


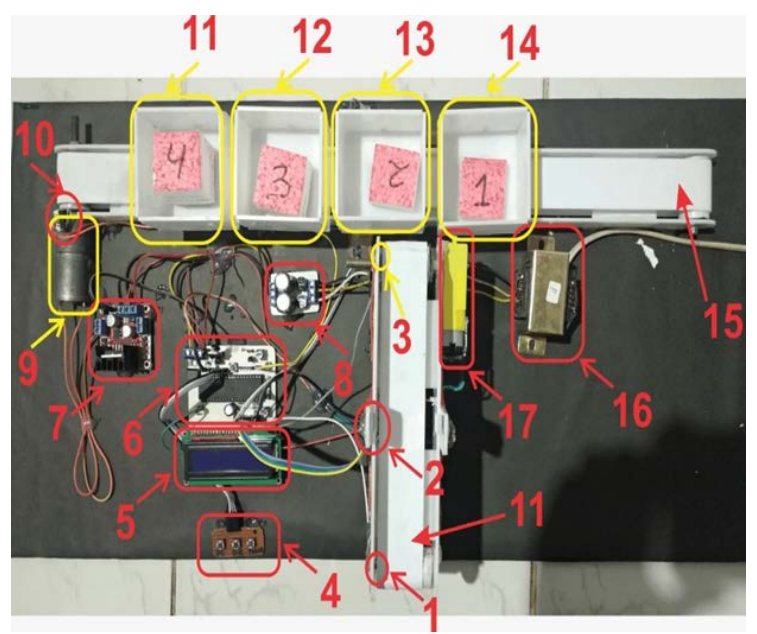

Gambar 3. Realisasi Hasil Perancangan

Keterangan

1. Sensor photodioda 1

2. Sensor photodioda 2

3. Sensor photodioda 3

4. Menu Botton

5. LCD ( Liquid Crystal Display)

6. Minsis ATMega 8535

7. Motor Driver L28

8. Regulator

9. Motor Dc

10. Limit Switch

11. Tempat box 4

12. Tempat box 3

13. Tempat box 2

14. Tempat box 1

15. Konveyor 2

16. Motor DC

\subsection{Pembahasan dan Pengujian}

Untuk mengetahui apakah minimum sistem ATMega 8535 ini dapat bekerja dengan baik maka harus menjalankan program AVR dengan menggunakan bahasa visual $\mathrm{C}++$ pada minimum sistem tersebut. Yang harus dilakukan sebelum proses running program adalah mendownload program pada mikrokontroler. Setelah melakukan proses Download program Test Led.Hex maka rangkaian LED pada Minimum System ATMega 8535 akan padam (PORTB=0b11111111;) selama 1 detik ( delay_ms(1000); ) kemudian LED menyala (PORTB=0b00000000;) selama 1 detik ( delay_ms(1000); ) begitu seterusnya selama tak terhingga. Hal ini membuktikan bahwa rangkaian minimum sistem ATMega 8535 bekerja dengan baik. Gambar 4 di bawah ini menunjukkan LED menyala dan padam.

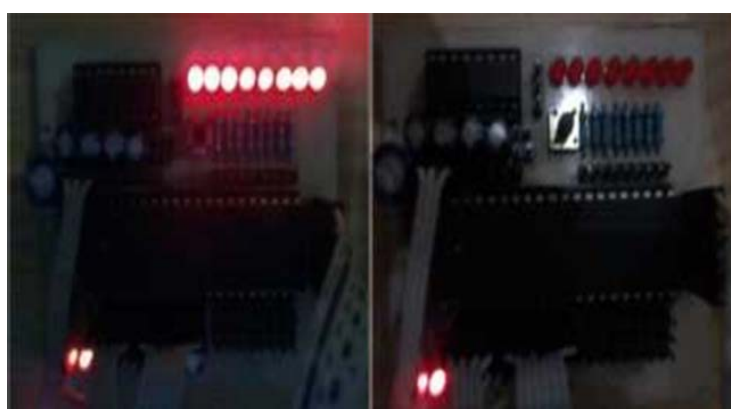

Gambar 4 LED pada saat menyala dan padam.

Pengujian dan pembahasan rangkaian LCD bertujuan untuk mengetahui apakah rangkaian LCD bekerja dengan baik sesuai perencanaan. Pada pengujian rangkaian LCD digunakan mikrokontroler ATMega 8535 dan LCD sebagai penampil karakter tulisan. Apabila karakter alphanumeric pada LCD berhasil ditampilkan, maka rangkaian LCD berfungsi dengan baik sesuai perencanaan. Berikut merupakan listing program yang digunakan untuk melakukan pengujian rangkaian LCD.

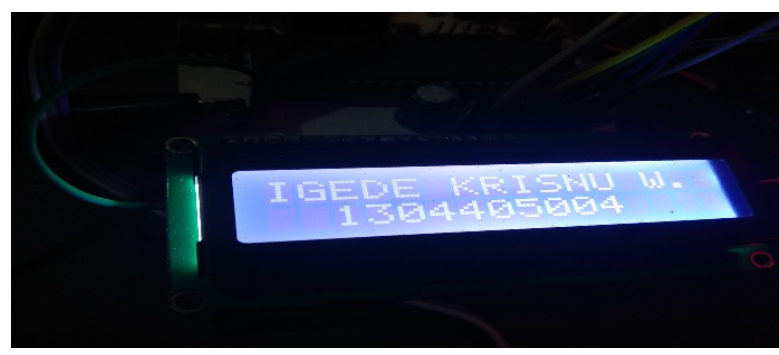

Gambar 5 Tampilan LCD Pengujian Rangkaian LCD

Sensor yang di gunakan dalam rangkaian penyeleksi barang dengan konveyor ini menggunakan sensor photodioda. Setelah di lakukan pengujian di dapatkan hasil sebagai berikut. Pengujian sensor photodioda ditunjukkan pada Tabel 1 sebagai berikut :

\begin{tabular}{|l|c|c|}
\hline \multicolumn{1}{|c|}{ Sensor } & $\begin{array}{c}\text { Saat ada Benda } \\
\text { (volt) }\end{array}$ & $\begin{array}{c}\text { Saat tidak ada } \\
\text { Benda } \\
\text { (volt) }\end{array}$ \\
\hline S1 & $5,0 \mathrm{v}$ & $0,19 \mathrm{v}$ \\
\hline T1 & $4,94 \mathrm{v}$ & $0,23 \mathrm{v}$ \\
\hline T2 & $4,9 \mathrm{v}$ & $0,22 \mathrm{v}$ \\
\hline T3 & $5,0 \mathrm{v}$ & $0,91 \mathrm{v}$ \\
\hline T4 & $4,98 \mathrm{v}$ & $0,66 \mathrm{v}$ \\
\hline T5 & $5,6 \mathrm{v}$ & $0,24 \mathrm{v}$ \\
\hline $\begin{array}{l}\text { Sensor } \\
\text { Counter }\end{array}$ & $5,05 \mathrm{v}$ & $4,13 \mathrm{v}$ \\
\hline
\end{tabular}

Tabel 1. Pengujian Sensor Photodioda 
Dari hasil pengujian sensor photodioda diatas sensor berfungsi dan siap untuk di gunakan.

\subsection{Pengujian Alat}

Dalam pengujian alat akan di lakukan sebanyak 10 kali pengujian dengan cara peletakan barang secara acak. Hasil pengujian di tunjukan pada Tabel 2 sebagai berikut :

\begin{tabular}{|c|c|c|l|}
\hline No & Benda & Indikator & Keterangan \\
\hline 1. & Benda $1 \mathrm{~cm}$ & Berhasil & $\begin{array}{l}\text { Benda berhasil } \\
\text { menuju box 1 }\end{array}$ \\
\hline 2. & Benda $2 \mathrm{~cm}$ & Berhasil & $\begin{array}{l}\text { Benda berhasil } \\
\text { menuju box 2 }\end{array}$ \\
\hline 3. & Benda 3cm & Berhasil & $\begin{array}{l}\text { Benda berhasil } \\
\text { menuju box 3 }\end{array}$ \\
\hline 4. & Benda 4cm & Berhasil & $\begin{array}{l}\text { Benda berhasil } \\
\text { menuju box 4 }\end{array}$ \\
\hline 5. & Benda $5 \mathrm{~cm}$ & Berhasil & $\begin{array}{l}\text { Benda berhasil } \\
\text { menuju box 4 }\end{array}$ \\
\hline 6. & $\begin{array}{c}\text { Benda } \\
0,5 \mathrm{~cm}\end{array}$ & Tidak & $\begin{array}{l}\text { Konveyor 1 } \\
\text { tidak bergerak }\end{array}$ \\
\hline 7. & $\begin{array}{l}\text { Benda } \\
1,5 \mathrm{~cm}\end{array}$ & Berhasil & $\begin{array}{l}\text { Benda berhasil } \\
\text { menuju box 2 }\end{array}$ \\
\hline 8. & $\begin{array}{l}\text { Benda } \\
2,5 \mathrm{~cm}\end{array}$ & Berhasil & $\begin{array}{l}\text { Benda berhasil } \\
\text { menuju box 3 }\end{array}$ \\
\hline 9. & Benda 3cm & Berhasil & $\begin{array}{l}\text { Benda berhasil } \\
\text { menuju box 3 }\end{array}$ \\
\hline 10. & Benda 4cm & Berhasil & $\begin{array}{l}\text { Benda berhasil } \\
\text { menuju box 4 }\end{array}$ \\
\hline
\end{tabular}

Tabel 2 Pengujian Alat

Pada tahap pengujian alat setiap sample uji barang memiliki tinggi yang berbeda dari $1 \mathrm{~cm}$ sampai dengan $5 \mathrm{~cm}$. Sample uji akan bergerak otomatis menuju sensor photodioda dan berhenti di ujung konveyor 1 dan jatuh ke konveyor 2 . Sample uji yang memiliki tinggi $1 \mathrm{~cm}$ sampai dengan 4cm akan menuju boxnya masing masing dan box yang ada di konveyor 2 akan kembali ke posisi semula karena box sudah terisi dengan barang. Sampe uji yang memiliki tinggi $0,5 \mathrm{~cm}$ tidak dapat di ukur karena tinggi barang tersebut tidak dapat menutupi sensor dan konveyor akan bergerak jika sensor di tutupi oleh barang, minimal tinggi yang dapat di ukur adalah $1 \mathrm{~cm}$. Sedangkan untuk tinggi barang $1,5 \mathrm{~cm}$ akan menuju box 2 karena tinggi barang melebihi $1 \mathrm{~cm}$ dan menutupi sensor ke 2 yang mengukur tinggi barang $2 \mathrm{~cm}$. Untuk tinggi $2,5 \mathrm{~cm}$ akan menuju box 3. Untuk tinggi $5 \mathrm{~cm}$ keatas akan menuju box karena yang di ukur hanya tinggi $1 \mathrm{~cm}$ sampai $4 \mathrm{~cm}$. Hasil sensor barang akan di tampilkan di layar LCD dengan menampilkan tinggi barang.

\section{KESIMPULAN}

Dari tahap perancangan, pembuatan dan pengujian yang telah dilakukan dapat diambil kesimpulan bahwa Konveyor 1 akan bergerak jika ada barang atau benda yang di letakan di depan konveyor 1 dan berhenti ketika barang berada di ujung konveyor 1 . Konveyor 2 akan bergerak jika sensor photodioda sudah mendeteksi tinggi barang yang ada di konveyor 1 . Sensor photodioda sudah bekerja dengan baik bila hanya di gunakan untuk mengukur tinggi benda atau barang. Alat ini hanya dapat mengukur tinggi barang maka dari itu bisa di kembangkan missal warna atau berat barang.

\section{DAFTAR PUSTAKA}

[1] Afrie Setiawan, Mikrokontroller Atmega 8535,Andi offset, Yogyakarta, 2010. Pusat data dan informasi energy dan sumber daya mineral KESDM, Jakarta 2010

[2] Bishop, O. 2004. Dasar-Dasar Elektronika. Jakarta: Erlangga

[3] Brian eka bhuana, Purwarupa Sistem Sorting Barang Berdasarkan Warna Menggunakan Mikrokontroler ATMEGA16 Dengan Sensor Photodioda, etd.repository.ugm.ac, Diakses tanggal 11 november 2017).

[4] Conveyor equipment Manufactures Asscociation ., 1979 , Belt conveyor for bulk Material

[5] Debit zein Ariandana, Epyck sunarno,STT MT. Politeknik ELektronika Negeri Surabaya, yang berjudul ' Rancang Bangun konveyor Untuk Sistem Sortir Barang berdasarkan Berat Barang'

[6] Fikri, Afrizal.2015. Monitoring real time kecepatan motor dc Menggunakan PWM . Tugas akhir , ITENAS. Bandung.

[7] Lingga wardhana, Mikrokontroller AVR seri Atmega 8535, Andhi offset, Yogyakarta, 2010

[8] Pardue, Joe. 2005. C Programming for AVR Microcontroller. Knoxville : Smiley Micros.

[9] Riyanto, Sigit. 2008. Sensor dan Aktuator. Yogyakarta : Graha Ilmu.

[10] Suyadhi, Septian, Dwi, Taufiq. 2008. Build your own line follower robot. CV Andi Offset: Bandung. 